\title{
Scinax ruber (Red-snouted Treefrog).
}

\section{Distribution.}

Date of observation: 27 May 2011. Location: Puerto Rico: Cabo Rojo; Boquerón. Coordinates: 18.032011, -67.173192. Elevation: 2 m. Voucher: image. After heavy rains (more than 10 inches) a small pond formed. There were five males calling and one female was seen. Land usage is for cattle pasture, with scattered trees. This is a range extension for this introduced, invasive, species to the southwestern corner of the island. Identification verified by Jose A. Colon.

Alcides L. Morales, Puerto Rican Ornithological Society Inc., 1605 Carr 477, Quebradillas, Puerto Rico, 678, Puerto Rico, alcidesl.morales@yahoo.com.

Citation: Morales AL. 2011. Scinax ruber (Red-snouted Treefrog). Distribution. Caribbean Herpetology 21:1.

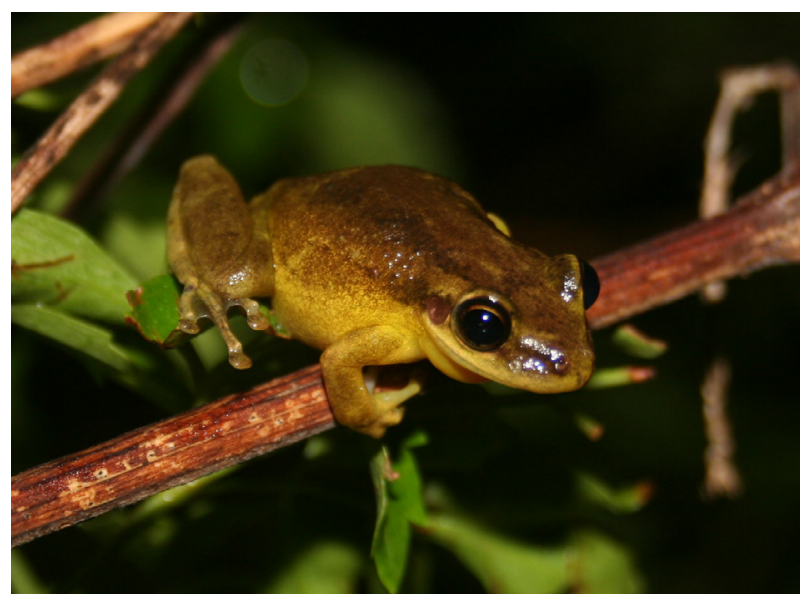

Published online 20 June 2011 